American Journal of Pharmacology and Toxicology 4 (4): 151-157, 2009

ISSN 1557-4962

(C) 2009 Science Publications

\title{
The Efficacy of Karkadeh Tea in Controlling Post-Prandial Blood Glucose Levels
}

\author{
${ }^{1}$ Adrian Paul Harrison, ${ }^{2}$ Ross Gordon Cooper, ${ }^{3}$ Moustafa Ahmed Suliman and ${ }^{4}$ Usama AlAlami \\ ${ }^{1}$ Section for Biochemistry and Physiology, Department of Animal and Veterinary Basic Sciences, \\ Faculty of Life Sciences, Copenhagen University, 1870 Frederiksberg C, Denmark \\ ${ }^{2}$ Physiology Division, Birmingham City University, Edgbaston Campus, \\ 030 Bevan House, Westbourne Road, Edgbaston, Birmingham B15 3TN, UK \\ ${ }^{3} 12$ Ekhwan Salem St., Shoubra El Khema, Egypt \\ ${ }^{4}$ Department of Natural Science and Public Health, College of Arts and Sciences, \\ Zayed University, P.O. Box 19282, Dubai, UAE
}

\begin{abstract}
Problem statement: Increasing interest from the general public to use herbal remedies, exposes a considerable need to document ancient medical practices, as well as to investigate the efficacy of "ancient" compounds currently reputed to have medicinal benefits for such diseases as diabetes and obesity. Approach: In order to investigate the efficacy of "karkadeh" RoselleHibiscus sabdariffa tea as a means of reducing post-prandial blood glucose levels in human subjects, $10 \mathrm{~g}$ of dried karkadeh was brewed in $500 \mathrm{~mL}$ of water, allowed to infuse for $60 \mathrm{~min}$ and imbibed along with a high glycemic index food. Results: Data showed that in one individual, karkadeh tea taken in connection with a carbohydrate based breakfast meal resulted in a significant increase (17\%; $\mathrm{p}<0.01)$ in blood glucose level $c f$. an ordinary breakfast tea $60 \mathrm{~min}$ after ingestion. Moreover, in a study involving eight individuals, a slower rise to maximum levels and a greater Area Under the Curve (AUC) in terms of blood glucose was noted for the karkadeh tea plus a high glycemic index food cf. that of water imbibition with an identical high glycemic food. Conclusion/Recommendations: Karkadeh tea appears to have an effect in terms of slowing the rate of rise in blood glucose following consumption of a high glycemic index food, but that ultimately it induces a greater degree of glucose absorption $c f$. other types of imbibed fluids.
\end{abstract}

Key words: Egyptian, Hibiscus sabdariffa, karkadeh, slimness

\section{INTRODUCTION}

Perhaps as many as $60 \%$ of Americans are overweight and this has given rise to interest in compounds that can reduce dietary sugar absorption in vivo. One such compound is lectin from the kidney bean (Phaseolus vulgaricus Linn.), a glycoprotein that is well known for its ability to bind sugars at low levels, thus impairing their intestinal absorption ${ }^{[7]}$. However, lectins are potent mitogens and can even become cytotoxic at higher levels of intake, which become necessary if they are to be effective as sugar blockers.

Clearly another natural alternative to lectins is needed and this might be available in the form of Hibiscus sabdariffa L. (English: Roselle, red sorrel; Arabic: karkadeh), which has been tried and tested for more than 3000 years. The calyces of roselle have been and indeed still are used in many parts of the world to make cold and hot drinks, being quite healthy owing to the drinks high ascorbic acid (vitamin C) content $^{[4]}$. Moreover, in folk medicine, the calyx extracts are used for the treatment of several complaints, including high blood pressure, liver diseases and fever ${ }^{[4]}$.

Historical background: Roselle-Hibiscus sabdariffa Linn., known in Arabic as "Karkadeh", is an edible medicinal plant native to India, China and Thailand, which is commonly used in Ayurveda and traditional medicine ${ }^{12]}$. However, it has recently come to the author's attention that the ancient Egyptians of the Middle Kingdom also relied on this plant, which is reportedly only to be found in the Aswan region. It was used by the ancient Egyptian Kings and is still in use by the locals even today. A preparation of the petals and flower of this plant as an aqueous extraction or "tea" gives rise to a red-coloured drink, which should be imbibed whilst cool, being relatively tasteless (Fig. 1).

Corresponding Author: Adrian Paul Harrison, Section for Biochemistry and Physiology,

Department of Animal and Veterinary Basic Sciences, Faculty of Life Sciences,

Copenhagen University, 1870 Frederiksberg C, Denmark Tel: 004535332568 Fax: 004535332525 


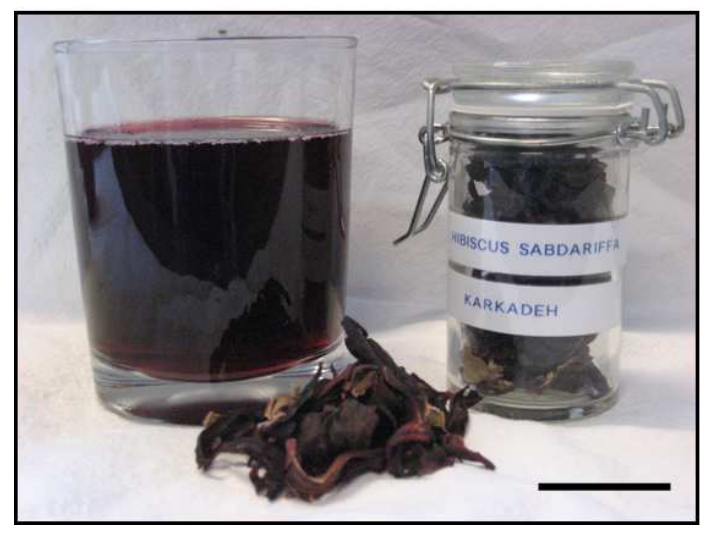

Fig. 1: Dried petals of Roselle, known in Arabic as "Karkadeh" (Hibiscus sabdariffa Linn)collected from the Aswan region of Egypt. The photo was taken using a Canon Digital Ixus 60 camera with 6.0 megapixel resolution, on the 30th of April 2008; shutter 1/60, f/3.5, focal length $8.4 \mathrm{~mm}$. Scale bar $=5 \mathrm{~cm}$

In Egypt, during the hot summer months, numerous traditional drinks such as karkadeh are consumed and are known to have a beneficial effect on human health ${ }^{[16]}$. However, a decreasing preference for the old and more traditional ways and a move towards an increasing use of commercially produced carbonated drinks, soft drinks and fruit nectars has resulted in elevated blood glucose levels with deleterious effects to the health and well-being of the general populace ${ }^{[16]}$.

Of particular interest is the fact that Roselle tea has recently been shown to have a pancreatic $\alpha$-amylase inhibitory action, which appears to be attributable to its hibiscus acid content ${ }^{[15]}$.

Thus, it is with these aspects in mind that we have sought to test the effects of karkadeh tea made from Hibiscus sabdariffa collected from Aswan, on blood glucose levels in two separate trials in human subjects. Our working hypothesis being that karkadeh consumption in connection with a high glycemic index food reduces post-prandial blood glucose levels $c f$. other forms of fluid intake.

\section{MATERIALS AND METHODS}

The human volunteers recruited for the single and multiple subject studies gave their informed consent and the study was conducted in accordance with the Declaration of Helsinki. Furthermore, permission was granted by Zayed University to allow us to undertake the glucose determinations on some volunteer participants aged 18 and over.
Single subject repeat study: For the blood glucose and Roselle (Hibiscus sabdariffa) breakfast plus tea trial, a single male human volunteer was recruited.

The volunteer was subsequently provided with a Freestyle Lite blood glucose monitoring system (DBMK301-C0165, Abbott Diabetes Care Inc., Alameda California, USA) and instructed in its use. The volunteer was then told to follow a strict routine of blood glucose measurement upon awakening in the morning and to repeat this measurement 60 min after consuming a breakfast meal. The subject was provided with $100 \mathrm{~g}$ portions of a commercial breakfast cereal (sugar coated flakes of maize: 375.7 calories energy, $4.5 \mathrm{~g}$ protein, $87 \mathrm{~g}$ of soluble carbohydrate and $0.6 \mathrm{~g}$ fat-per $100 \mathrm{~g}$ portion), which he consumed with a small quantity of skimmed milk and a $250 \mathrm{~mL}$ volume of either an English Breakfast tea, or an equal volume of Roselle tea, which was provided for him. The subject then repeated this procedure over a 6 day period, carefully recording the blood glucose values as they were taken. It should also be noted that the subject remained relatively inactive over the period of measurement, undertaking only sedentary work at a desk.

Multiple subject study: Volunteers for this study were also provided with a Freestyle Lite blood glucose monitoring system (DBMK301-C0165, Abbott Diabetes Care Inc., Alameda California, USA) and instructed in its use. The subjects consumed a high Glycemic Index (GI) food on two occasions (chocolate coated toffee and caramel bar: 449 calories energy, $4.2 \mathrm{~g}$ protein, $69 \mathrm{~g}$ of soluble carbohydrate and $17.4 \mathrm{~g}$ fat-per $100 \mathrm{~g}$ portion) with a $250 \mathrm{~mL}$ volume of water and then subsequently on the following day, with an equal volume of Roselle tea. In this way the subjects acted as their own control. Blood glucose measurements were made at time zero (before ingestion of food or drink) and at $10,20,30,45$ and $60 \mathrm{~min}$ subsequent to consuming the high glycemic index food. Finally, as with the previous single subject repeat study, it should be noted that the subjects remained relatively inactive over the period of measurement.

Hibiscus sabdariffa tea preparation: A $10 \mathrm{~g}$ quantity of dried Hibiscus sabdariffa petals, obtained from the Aswan region of Egypt, were immersed into $500 \mathrm{~mL}$ of boiling water and left to infuse the water for a period of $60 \mathrm{~min}$. After this time the petals were removed and the now scarlet-red solution was bottled and stored at $4{ }^{\circ} \mathrm{C}$ until used.

A measurement of the $\mathrm{pH}$ of the infused Hibiscus sabdariffa tea revealed a value of 2.5 using triplesquare $\mathrm{pH}$-indicator strips (non-bleeding) which were 
allowed to stabilize for a period of $10 \mathrm{~min}$ before being read from the colorimetric scale that came with the strips (Merck, D-6100 Darmstadt, Germany).

Blood glucose measurements: Blood glucose concentration was measured in blood samples taken after a finger prick with a sterile surgical lancet (Freestyle-Abbott Diabetes Care Inc., Alameda California, USA). A drop of blood $(0.3 \mu \mathrm{L})$ was introduced on to a Test-Strip, which was inserted into a Freestyle Lite blood glucose monitoring system (DBMK301-C0165, Abbott Diabetes Care Inc., Alameda California, USA). The system, which gave a result within $5 \mathrm{sec}$ of applying blood to the Test Strip, had a sensitivity range of 1.1-27.8 mmol $\mathrm{L}^{-1}$ blood glucose and relied on a colometric electrochemical analytical sensor. It should also be noted that this type of equipment had an inherent variation in terms of reliability of repeat measurements in the order of $\pm 10 \%$.

Statistical analysis: Data were presented as means \pm SE. Normality in the data set was assessed using a Kolmogorov-Smirnov test and differences between means were tested for statistical significance using a Paired two-tailed t-test-GraphPad InStat Version 3.0 b (Sept. 2003) for Macintosh, GraphPad Software, San Diego California, USA. Differences showing a p-value $>0.05$ were considered non-significant.

\section{RESULTS}

Single subject repeat study: The single subject, who was 43 years-old and who weighed $90 \mathrm{~kg}$, was neither diabetic nor from a family with a history of diabetes.

In Table 1 the data collected from a series of six daily repeats performed over a 12 day period in one individual, showed a significant $(\mathrm{p}<0.01)$ increase in blood glucose concentration $60 \mathrm{~min}$ after ingesting a breakfast meal with a $250 \mathrm{~mL}$ volume of English Breakfast tea or Hibiscus tea. Moreover, a comparison of the breakfast meal with Hibiscus tea rather than English Breakfast tea resulted in a significant $(\mathrm{p}<0.01)$ $1.2 \mathrm{mM}$ higher blood glucose concentration at the 60 min post-prandial recording time.

Multiple subject study: Data were analyzed for 8 subjects, of which 4 were female (age range: 1843 years, mean: $28.6 \pm 3.9$ years). The subject group as a whole measured on average $172.6 \pm 4.9 \mathrm{~cm}$ in height and weighed $81.8 \pm 6.1 \mathrm{~kg}$. Average BMI for the subjects was $27.4 \pm 1.6 \mathrm{~kg} . \mathrm{m}^{-2}$, where normal values fell between 18.5 and 24.9 and one third of the subjects were found to have a BMI below 24.9.
Table 1: Measurement of an increase in blood glucose concentration post "breakfast" in combination with either English breakfast tea (Control) or Karkadeh tea

\begin{tabular}{|c|c|c|c|c|}
\hline & $\begin{array}{l}\text { Overnight } \\
\text { fast blood } \\
\text { glucose } \\
\text { level } \\
\left(\mathrm{mmol} \mathrm{L}^{-1}\right)\end{array}$ & $\begin{array}{l}\text { Post meal* } \\
(60 \text { min }) \\
\text { blood } \\
\text { glucose level } \\
\left(\mathrm{mol} \mathrm{L}^{-1}\right)\end{array}$ & $\begin{array}{l}\text { Delta } \\
\text { increase } \\
\left(\mathrm{mol} \mathrm{L}^{-1}\right)\end{array}$ & $\begin{array}{l}\text { Statistical } \\
\text { Significance** }\end{array}$ \\
\hline Control $(n=6)$ & $5.32 \pm 0.18$ & $7.03 \pm 0.51$ & 1.65 & $\mathrm{P}=0.01$ \\
\hline Karkadeh $(n=6)$ & $5.58 \pm 0.10$ & $8.23 \pm 0.43 * * *$ & 2.65 & $P=0.01$ \\
\hline
\end{tabular}

$\mathrm{n}=6$ indicates the number of repeats performed on the same individual subject. *: $100 \mathrm{~g}$ of sugar coated cornflakes; $1578 \mathrm{~kJ}$ energy, $4.5 \mathrm{~g}$ protein, $87 \mathrm{~g}$ carbohydrate and $0.6 \mathrm{~g}$ fats; **: Differences between means were assessed for statistical significance using a Paired t-test after ensuring normality with a Kolmogorov-Smirnov test; ***: Mean is significantly different from that of the Control group at $60 \mathrm{~min}$ post meal $(\mathrm{p}<0.01)$

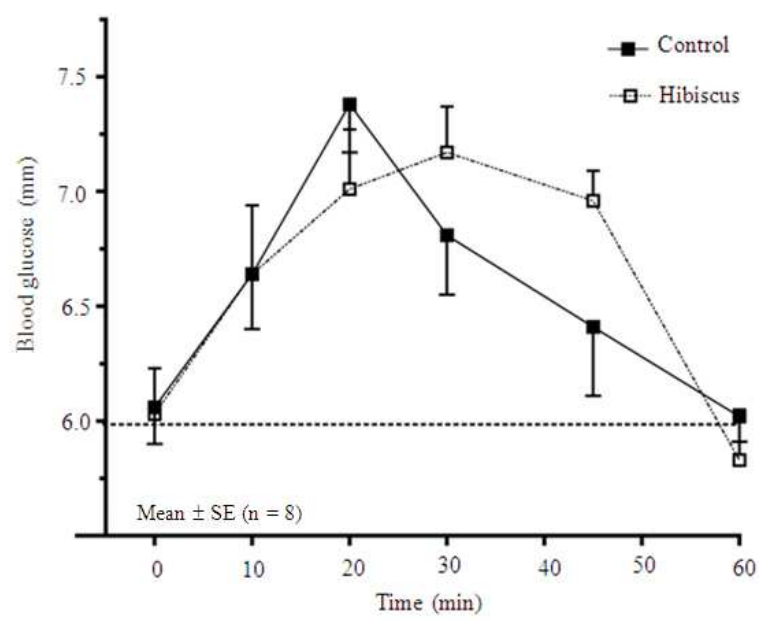

Fig. 2: A time course for blood glucose concentration post-prandial in subjects imbibing water

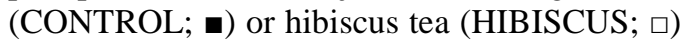
with their meal. The dotted line represents the baseline blood glucose values (pre-meal) for the group. The AUC for the Control group was 36.93, whilst the AUC for the Hibiscus group was 44.78 . Values are mean \pm SEM of 8 subjects

In Fig. 2, the curves for the Control and the Hibiscus groups $(n=8)$ were not found to be significantly different, despite a clear trend towards a slower yet greater glucose uptake following ingestion of a meal with Hibiscus tea rather than water.

Analysis of Fig. 2 in terms of the Area Under the Curve (AUC) revealed a value of 36.93 for the control group, whilst the AUC for the Hibiscus group was 44.78, which represents a $20 \%$ increase in the Hibiscus group Vs controls.

Data analysis: The power of the data presented in Fig. 2 was calculated to be between 30 and $40 \%$ for the SD 
and deltas of the means at the following time points; 20 , 30 and $45 \mathrm{~min}$. In order for these deltas $(0.37,0.36$ and 0.55 Control vs. Hibiscus at 20, 30 and $45 \mathrm{~min}$, respectively) to be found significantly different with a confidence of $90 \%$ and the current level of variance, a sample size of some 40 subjects would most likely be required.

Classification of sourced literature: The literature cited in this manuscript was sourced and selected according to dated impact factor, methodological association, relevance of results and statistical data, as well as the region in which the study was undertaken.

\section{DISCUSSION}

Clearly karkadeh tea has been used from a human health perspective for more than 3,500 years. In the present study it has been found that karkadeh tea results in a significantly $(\mathrm{p}<0.01)$ higher blood glucose level post-prandially $(60 \mathrm{~min})$ in repeat experiments in a single healthy individual and that whilst no significant effect was found for a multiple subject study, there was a trend towards a slower rate of increase in blood glucose to a maximum level post prandially and a larger AUC with karkadeh tea, than occurred with imbibition of water.

Blood glucose levels: A blood glucose level of $7.0 \mathrm{mM}$ or greater after a prolonged period of fasting is considered diagnostic of diabetes. Indeed, in normal healthy individuals a post-prandial blood glucose concentration exceeding $7.8 \mathrm{mM}$ at $1 \mathrm{~h}$ is quite rare ${ }^{[21]}$. Whilst in type II diabetes patients, fasting blood glucose levels $>110 \mathrm{mg} \mathrm{dL}^{-1}(6.1 \mathrm{mM})$ are associated with substantial cardiovascular risk ${ }^{[1]}$, as is detection of high levels of $\mathrm{HbA}_{1 \mathrm{c}}{ }^{[22]}$.

In the present study, however, normal resting "inter-meal" levels of blood glucose, comparable to those reported in the literature (3.9-6.1 mM) were found $^{[1]}$, despite the fact that two-thirds of the subjects had a BMI of 25 or above.

Food classification: Diets/foods with a high Glycemic Index (GI) cause rapid and strong increases in bloodsugar levels, which have been linked to an increased risk of diabetes. Thus, compounds capable of reducing, or alleviating this effect of high glycemic index foods is desirable.

The glycemic index for a food is measured by feeding a known portion of a carbohydrate meal and then following blood glucose levels at regular intervals.
Table 2: The glycemic index of some common foods

\begin{tabular}{lll}
\hline Breakfast cereals & Cornflakes 77 & Weetabix 75 \\
Grains pasta & Rice 50 & Spaghetti 41 \\
Bread & White 70 & Wholemeal 77 \\
Vegetables & Carrots 49 & Baked Potato 85 \\
Legumes & Butter Beans 31 & Kidney Beans 27 \\
Fruit & Apple 36 & Banana 60 \\
& Orange 43 & Grapes 43 \\
Dairy Foods & Whole Milk 27 & Yoghurt 33 \\
Confectionary & Chocolate 49 & Mars Bar 68 \\
Sugars & Honey 58 & Sucrose 59 \\
\hline
\end{tabular}

Source: Foster-Powell and Brand Miller ${ }^{[1 / 4}$

Thus the GI can be seen as a measure of the type of carbohydrates in a particular food, as well as how fast $50 \mathrm{~g}$ of a particular carbohydrate induces a rise in blood glucose levels upon being digested.

Other studies refer to the so-called Glycemic Load (GL), which is the application of GI to a standard serving of a particular food. Thus, a "Mars Bar" which has been measured as having a GI of 68 , making it a "high" GI food can be determined as having a GL of 23 based on the calculation $[(68 / 100) \times 34.5]$; where $34.5 \mathrm{~g}$ represents the carbohydrate content per $50 \mathrm{~g}$ of "Mars Bar". For a comparison of the GI values of some common foods, see Table $2^{[14]}$.

Carbohydrate intake varies according to athletic demands and with diverse sporting activities. Athletes, for instance, should aim to meet carbohydrate needs during training regimens and thus maximise the restoration of their muscle glycogen stores. Indeed, a pre-event meal is necessary to increase carbohydrate availability prior to prolonged exercise sessions at 1$4 \mathrm{~g} \mathrm{~kg}^{-1} \mathrm{BM}$ eaten 1-4 h prior to exercise. Furthermore, chronic or indeed every-day situations may necessitate daily glycogen store recovery or fuel needs for those athletes participating in moderate exercise programmes (i.e., $<1 \mathrm{~h}$ or exercise of low intensity) at $5-7 \mathrm{~g} \mathrm{~kg}^{-1}$ $\mathrm{BM}$ day $^{-1[8]}$.

Karkadeh and blood glucose regulation: Hyperglycemia, at least within the first $30 \mathrm{~min}$ following ingestion of a meal, has been suggested as being glucotoxic ${ }^{[21]}$. This is primarily based on the known effects of hyperglycemia ${ }^{[17]}$ and the fact that even individuals with a good dietary control of diabetes have a diminished release of insulin over the first half an $\mathrm{h}$ following a meal ${ }^{[20]}$.

Thus the trend shown in this study for the multiple subject trial of a slower rate of rise in blood glucose concentration (10-30 $\mathrm{min})$ to a maximum level, following consumption of a high glycemic index food with karkadeh tea may be of importance for such diabetic subjects. Furthermore, the very real possibility that 
karkadeh tea, taken in conjunction with low glycemic index foods, which are currently recommended for diabetics $^{[11]}$, should be explored as this may provide a means of inducing a greater reduction in the early rate of rise in blood glucose concentration reported in such individuals.

Hypoglycemia, on the other hand, also known as "low blood glucose" or "low blood sugar", occurs when blood glucose drops below normal levels. A recent review highlighted the risk of hypoglycemia in patients admitted to an intensive care or intermediate care ward, where tight glycemic control was imposed, whilst patients with septic shock and those with neurologic compromise are also at risk of experiencing hypoglycemia events ${ }^{[13]}$. Also at risk of developing hypoglycemia, are geriatric patients with type 2 diabetes mellitus, in which glycemic control is achieved by pharmacological means ${ }^{[18]}$. In such elderly patients there is a very real risk of pharmacological side effects, drug-disease and drug-drug interactions which could induce hypoglycemic periods. In the light of the current findings, which indicate a significant $(\mathrm{p}<0.01) \quad 17 \%$ increase in blood glucose levels 60 min after a breakfast meal when consumed with karkadeh tea rather than English Breakfast tea, it would seem that the role and use of karkadeh tea in such patients should be the focus of future studies, particularly as this study appears to indicate that the post-prandial blood glucose rise is slower and longer sustained with karkadeh tea.

Scientific evidence of other effects of karkadeh: Besides its reputed effects in terms of glucose absorption, karkadeh has been the focus of numerous other scientific investigations, some of them contradictory. For an overview of the effects of Hibiscus sabdariffa in terms of the treatment of certain obesity comorbidities including hyperlipidemia and elevated blood glucose levels see Dickel et al. ${ }^{[10]}$.

In an early study Hibiscus sabdariffa resulted in a significant $(\mathrm{p}<0.01)$ decrease in serum creatinine, cholesterol and glucose in treated rats compared with controls as well as a significant $(\mathrm{p}<0.01)$ increase in serum uric acid ${ }^{[19]}$. More recently, oral administration of an alcoholic extract of Hibiscus sabdariffa at a concentration of $250 \mathrm{mg} \mathrm{kg}^{-1}$ body weight has been found to normalize levels of ammonia, urea, uric acid, creatinine and non-protein blood nitrogen ${ }^{[12]}$. The administered extract was also found to elevate levels of catalase, superoxide dismutase, glutathione peroxidase and reduce glutathione in hyper-ammonemic rat brains $^{[12]}$.

Hibiscus sabdariffa attenuates body weight gain in obese mice and increases fluid intake in healthy obese mice, resulting in elevated Alanine Aminotransferase (ALT) levels on days 15 and 45 of treatment. These authors, however, found that triglycerides and cholesterol levels were not significantly affected ${ }^{[3]}$.

Extracts of Hibiscus sabdariffa in combination with vitamin $\mathrm{C}$ have been found to increase the antioxidant defence systems of rats and reduce the incidence of organ damage ${ }^{[2]}$. Treatment with vitamin $\mathrm{C}$ and Hibiscus sabdariffa (400 $\mathrm{mg} \mathrm{kg}^{-1}$ ) significantly decreased serum ALT activity $(\mathrm{p}<0.05)$. In addition, treatment with vitamin $\mathrm{C}$ and Hibiscus sabdariffa (400 and $\left.800 \mathrm{mg} \mathrm{kg}^{-1}\right)$ significantly $(\mathrm{p}<0.05)$ elevated the levels of reduced glutathione by 41 and $44 \%$, respectively, at 5 weeks ${ }^{[2]}$.

In other fields of research, pre-treatment with an aqueous extract of Hibiscus sabdariffa has been shown to result in significantly $(\mathrm{p}<0.01)$ less hepatotoxicity and to protect rats against cadmium-induced liver, prostate and testis lipoperoxidation ${ }^{[6]}$. Moreover, Hibiscus sabdariffa treatment increases the activity of testicular antioxidant enzymes and restores sperm motility in cisplatin-treated rats ${ }^{[5]}$.

Finally, experiments carried out on rats and rabbits have demonstrated the unequivocal antihypercholesterolaemic, anti-nociceptive and antipyretic effects of Hibiscus sabdariffa, although no antiinflammatory effects were noted ${ }^{[4]}$. Additionally, calyx extracts applied to smooth muscle in vitro appear to inhibit the resting tone of isolated muscles and oil extracted from the seeds of Hibiscus sabdariffa has been shown to have an inhibitory effect on the in vitro growth of certain bacteria and fungi ${ }^{[4]}$.

\section{CONCLUSION}

This study indicates that in contrast with herbal folklore, karkadeh tea taken in connection with a rapidly soluble carbohydrate meal results in a significant increase in blood glucose and not an inhibition. Whilst further studies of the use and dose of karkadeh in connection with other food types and larger cohorts are now needed, we tentatively conclude that karkadeh tea may have a beneficial effect in terms of slowing the rate of rise in blood glucose following consumption of a high glycemic index food and that this in itself may be of importance in terms of reducing post-prandial hyperglycemia and its links with insulin resistance and cardiovascular disease ${ }^{[1,21]}$. Moreover, karkadeh should now be investigated as a means of improving glycemic control in patients at risk of hypoglycemia. 
Am. J. Pharm. \& Toxicol., 4 (4): 151-157, 2009

\section{ACKNOWLEDGEMENT}

The researchers are grateful to the participants and to Stig Mølsted for a thought provoking discussion.

\section{REFERENCES}

1. AACE, 2002. American College of Endocrinology: Consensus statement on guidelines for glycemic control. Endocrin. Prac., 8: 6-11. http://www.aace.com/meetings/consensus/dcc/pdf/ dccwhitepaper.pdf

2. Adaramoye, O., B. Ogungbenro, O. Anyaegbu and M. Fafunso, 2008. Protective effects of extracts of vernonia amygdalina, Hibiscus sabdariffa and vitamin $\mathrm{C}$ against radiation-induced liver damage in rats. J. Radiat. Res. (Tokyo), 49: 123-131. http://www.jstage.jst.go.jp/article/jrr/49/2/49_123/ _article

3. Alarcon-Aguilar, F.J., A. Zamilpa, M.D. Perez-Garcia, J.C. Almanza-Perez and E. Romero-Nuñez et al., 2007. Effect of Hibiscus sabdariffa on obesity in MSG mice. J. Ethnopharmacol., 114: 66-71. http://www.ncbi.nlm.nih.gov/pubmed/17765418

4. Ali, B.H., N. Al Wabel and G. Blunden, 2005. Phytochemical, pharmacological and toxicological aspects of Hibiscus sabdariffa L.: A review. Phytother. $\quad$ Res., 19: 369-375. http://www.ncbi.nlm.nih.gov/pubmed/16106391

5. Amin, A. and A.A. Hamza, 2006. Effects of Roselle and Ginger on cisplatin-induced reproductive toxicity in rats. Asian J. Androl., 8: 607-612. http://www.ncbi.nlm.nih.gov/pubmed/16751998

6. Asagba, S.O., M.A. Adaikpoh, H. Kadiri and F.O. Obi, 2007. Influence of aqueous extract of Hibiscus sabdariffa L. petal on cadmium toxicity in rats. Biol. Trace Elem Res., 115: 47-57. http://cat.inist.fr/?aModele $=$ afficheN\&cpsidt $=18689692$

7. Brudnak, M.A., 2002. Weight-loss drugs and supplements: Are there safer alternatives? Med. Hypotheses, 58: 28-33. http://cat.inist.fr/?aModele=afficheN\&cpsidt $=13453698$

8. Burke, L.M., 2007. Sports Nutrition. In: Essentials of Human Nutrition, Mann, J. and A. Stewart Truswell (Eds.). 3rd Edn., Oxford University Press, Oxford, ISBN: 0199290970, pp: 488.

9. Carvajal-Zarrabal, O., S.M. Waliszewski, D.M. Barradas-Dermitz, Z. Orta-Flores and P.M. Hayward-Jones et al., 2005. The consumption of Hibiscus sabdariffa dried calyx ethanolic extract reduced lipid profile in rats. Plant Foods Hum. Nutr., 60: 153-159. http://www.ncbi.nlm.nih.gov/pubmed/16395625
10. Dickel, M.L., S.M. Rates and M.R. Ritter, 2007. Plants popularly used for loosing weight purposes in Porto Alegre, South Brazil. J. Ethnopharmacol., 109: 60-71. http://www.ncbi.nlm.nih.gov/pubmed/16963210

11. Eriksson, K.F. and F. Lindgarde, 1991. Prevention of type 2 (non-insulin-dependent) diabetes mellitus by diet and physical exercise: The 6-year Malmo feasibility study. Diabetalogia, 34: 891-898. http://www.ncbi.nlm.nih.gov/pubmed/1778354

12. Essa, M.M. and P. Subramanian, 2007. Hibiscus sabdariffa affects ammonium chlorideinduced hyperammonemic rats. Evid. Based Comple. Alternat. Med., 4: 321-325. http://www.pubmedcentral.nih.gov/articlerender.fc gi? artid=1978237

13. Fahy, B.G., A.M. Sheehy and D.B. Coursin, 2009. Glucose control in the intensive care unit. Crit. Care Med., 37: 1769-1776. http://www.ncbi.nlm.nih.gov/pubmed/19325461

14. Foster-Powell, K. and J. Brand Miller, 1995. International tables of glycemic index. Am. J. Clin. Nutr., $\quad 62: \quad$ 871S-893S. http://www.ncbi.nlm.nih.gov/pubmed/7572722

15. Hansawasdi, C., J. Kawabata and T. Kasai, 2000. Alpha-amylase inhibitors from roselle (Hibiscus sabdariffa Linn.) tea. Biosci. Biotechnol. Biochem., 64: 1041-1043. http://www.ncbi.nlm.nih.gov/pubmed/10879476

16. Hassan-Wassef, H., 2004. Food habits of the Egyptians: Newly emerging trends. East Med. Health J., 10: 898-915. http://www.ncbi.nlm.nih.gov/pubmed/16335778

17. Jovanovic, L., 1999. Rationale for prevention and treatment of postprandial glucose-mediated toxicity. $\quad$ Endocrinology, 9: 87-92. http://direct.bl.uk/bld/PlaceOrder.do?UIN=060752 643\&ETOC $=$ RN\&from $=$ searchengine

18. Neumiller, J.J., S.M. Setter, B.J. Gates, T.E. Sonnett, E.K. Dobbins and K. Campbell, 2009. Pharmacological management of glycemic control in the geriatric patient with type 2 diabetes mellitus. Consult. Pharm., 24: 45-63. http://www.labmeeting.com/paper/28775405/neum iller-2009-pharmacological-management-of-glycemiccontrol-in-the-geriatric-patient-with-type-2-diabetesmellitus

19. Onyenekwe, P.C., E.O. Ajani, D.A. Ameh and K.S. Gamaniel, 1999. Antihypertensive effect of roselle (Hibiscus sabdariffa) calyx infusion in spontaneously hypertensive rats and a comparison of its toxicity with that in Wistar rats. Cell Biochem. Funct., 17: 199-206. DOI: 10.1108/00346650210445758 
20. Pfeifer, M.A., J.B. Halter and D. Porte Jr., 1981. Insulin secretion in diabetes mellitus. Am. J. Med., 70: 579-588.

http://www.annals.org/cgi/content/abstract/69/5/891

21. Rendell, M.S. and L. Jovanovic, 2006. Targeting postprandial hyperglycemia. Metab. Clinic. Exp., 55: 1263-1281.

http://cat.inist.fr/?aModele $=$ afficheN\&cpsidt $=1810$ 7151
22. Stratton, I.M., A.I. Adler, H.A.W. Neil, D.R. Matthews and S.R. Manley, 2000. Association of glycaemia with macrovascular and microvascular complications of type 2 diabetes (UKPDS 35): Prospective observational study. Br. Med. J., 321: 405-412.

http://www.bmj.com/cgi/content/full/321/7258/405 